\title{
A Prospective Study on Retinopathy of Prematurity in a Teritiary Care Center
}

\author{
Mahaboob Basha Kallur', K. Muralidhar ${ }^{2}$ \\ ${ }^{1}$ Associate Professor, Department of Pediatrics, Shadan Institute of Medical Sciences, Teaching hospital and research center, Himayath sagar Road, \\ Hyderabad, Telangana, ${ }^{2}$ Associate Professor, Department of Pediatrics, Rajiv Gandhi Institute of Medical Sciences, Adilabad, Telangana.
}

\section{Abstract}

Background: Retinopathy of prematurity (ROP) is a vaso-proliferative retinopathy which occurs mostly in premature babies. The pathological change in ROP is peripheral retinal neovascularisation which may regress completely or leave sequelae from mild myopia to bilateral total blindness. International classification of ROP helped in uniform documentation and staging of ROP. In India, the incidence of ROP is between 38 and 51.9 p.c among low-birth-weight infants. Aim \& Objectives: To estimate the incidence of ROP among premature and / or low birth weight babies who were born and admitted to neonatal intensive care unit and attending neonatal follow-up clinic. Subjects and Methods: A hospital based, prospective analytical cross-sectional study was conducted in Department of Pediatrics at Shadan Institute of Medical Sciences, Teaching hospital and research center, Hyderabad, Telangana for a period of 6 months from 1st October 2018 to 31st March 2019. Prior to the study initiation, ethical clearance was obtained and written consent was taken from the parents of the respective babies. The study subjects included premature babies (less than or equal to 35 weeks of gestation) or low birth weight babies (less than or equal to 1500 grams). A predesigned, pre-tested, semi-structured proforma was used to collected the data. The data was collected, entered in Microsoft excel-2013 and analyzed using SPSS version-22 (trial). Data was presented in percentages, proportions and figures. Result: The ROP incidence in the study group was reported among 17.1 p.c of the study subjects. Conclusion: Low birth weight and prematurity are important risk factors for ROP.

Keywords: Prematurity, Retinopathy.

Corresponding Author: Dr. K. Muralidhar, Associate Professor, Department of Pediatrics, Rajiv Gandhi Institute of Medical Sciences, Adilabad, Telangana.

Email: ajay_reddy52420@yahoo.com

Received: March 2020

Accepted: March 2020

\section{Introduction}

Retinopathy of prematurity (ROP) is a vaso-proliferative retinopathy which occurs mostly in premature babies. ${ }^{[1]}$ ROP is a disorder of the developing retinal blood vessels in the premature infant retina. The pathological change in ROP is peripheral retinal neovascularisation which may regress completely or leave sequelae from mild myopia to bilateral total blindness. ${ }^{[2]}$ International classification of ROP helped in uniform documentation and staging of ROP. ${ }^{[3]}$ The onset of ROP consists of two stages, the primary stage hyperoxia, is critical point in retinal vascularisation that results in vasoconstriction and subsequent arrest in vascular development. During the second stage, neovascularization occurs and this aberrant retinal vessel growth is thought to be driven by excess angiogenic factors. New vessels will grow through the retina into vitreous and extensive extra retinal fibro vascular proliferation can lead to retinal detachment. ${ }^{[4]}$ In India, the incidence of ROP is between 38 and 51.9 p.c among low-birth-weight infants. ${ }^{[5,6]}$ ROP screening guidelines included babies with birth weight less than 1500 grams or less than 32 weeks of gestation, also preterm infants with birth weight 1501-2000 grams or 32-34 weeks of gestation with an unstable clinical course, including those requiring cardiorespiratory support and who are believed by their attending paediatrician or neonatologist to be at higher risk. ${ }^{[7]}$

\section{$\underline{\text { Aim \& Objectives }}$}

- To estimate the incidence of ROP among premature and / or low birth weight babies who were born and admitted to neonatal intensive care unit and attending neonatal follow-up clinic.

\section{Subjects and Methods}

A hospital based, prospective analytical cross-sectional study was conducted in Department of Pediatrics at Shadan Institute of Medical Sciences, Teaching hospital and research center, Hyderabad, Telangana for a period of 6 months from $1^{\text {st }}$ October 2018 to $31^{\text {st }}$ March 2019. Prior to the data collection, ethical clearance was obtained from the Institutional Ethics Committee and written consent was taken from the parents of the respective babies. The study subjects included premature babies (less than or equal to 35 weeks of gestation) or low birth weight babies (less than or equal to 1500 grams) who were admitted to neonatal intensive care unit (NICU) and attending neonatal follow-up clinic at Shadan Institute of Medical Sciences, Teaching 
hospital and research center, Hyderabad. Babies who died before examination or before full vascularisation of retina, who did not complete follow-up, who had ocular disorders that interfere with fundus examination and those who were with other congenital retinal malformations were excluded from the study. About one hour before the scheduled examination, the pupils of the babies were dilated using $2.5 \%$ phenylephrine and $0.5 \%$ tropicamide eye drops instilled three times into each eye at intervals of 15 minutes. Resistance to dilation was noted carefully. An indirect ophthalmoscopy was performed by the Pediatric Ophthalmologist who was well trained in ROP screening using a 20D lens. A pediatric wire speculum was used to keep the eyelids apart and a scleral indenter to visualize the periphery. All aseptic precautions were taken. After decreasing the room illumination, first the posterior pole was visualized for plus disease. Then the periphery was examined to look for the extent of changes. Classification of ROP was done according to the international classification (ICROP). If no ROP was detected at initial examination, the infants were re-evaluated once every two weeks until vascularization was completed. If ROP was detected, the examinations were performed weekly for stage 1-2 disease and more frequently for stage- 3 disease, till the disease started resolving or progressed to threshold stage. Babies who reported an evidence of regression were followed until vascularization was complete. Babies progressing to threshold stage were referred. A predesigned, pre-tested, semi-structured proforma was used to collect the data. The data was collected, entered in Microsoft excel-2013 and analyzed using SPSS version-22 (trial). Data was presented in percentages, proportions and figures etc. Appropriate statistical tests were used where ever necessary.

\section{Results}

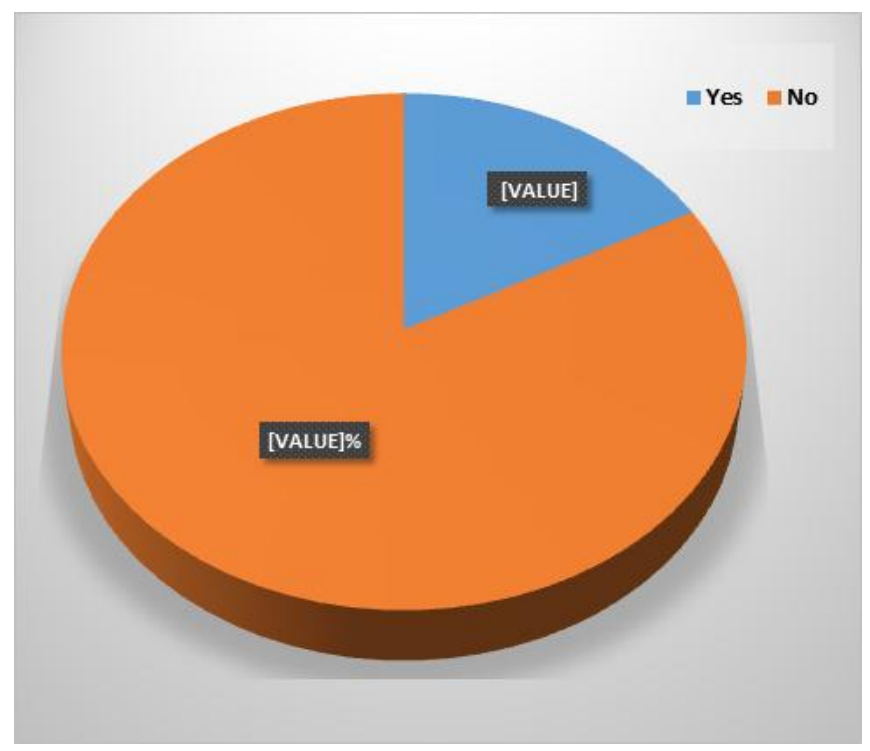

Figure 1: Incidence of ROP
In the present study a total number of 421 babies admitted in NICU \& attended neonatal follow-up clinic but only 35 babies fulfilled all criteria for screening of ROP and among them only 6 had ROP. The ROP incidence in the study group was reported among 17.1 p.c (6) of the subjects [Figure 1]. Among the thirty five study subjects, 15 (42.8 p.c) were males and 20 (57.2 p.c) were females. In figure-2 the distribution of ROP subjects based on the ROP stage depicts that majority 66.6 p.c (4) were in ROP stage-1 followed by 16.7 p.c (1) in ROP stage $2 \& 3$ each respectively. In table-1, comparison of various parameters with ROP was analyzed; oxygen administration, respiratory distress syndrome, exchange transfusion had a statistically significant association with ROP; birth weight, post conceptional age at first examination had a statistically significant difference with ROP respectively.

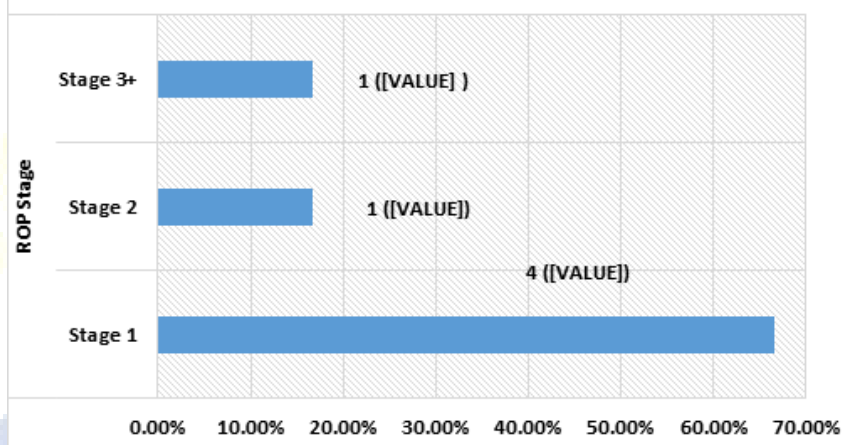

Figure 2: Distribution of ROP Subjects Based on ROP Stage

Table 1: Comparison of Various Parameters with ROP

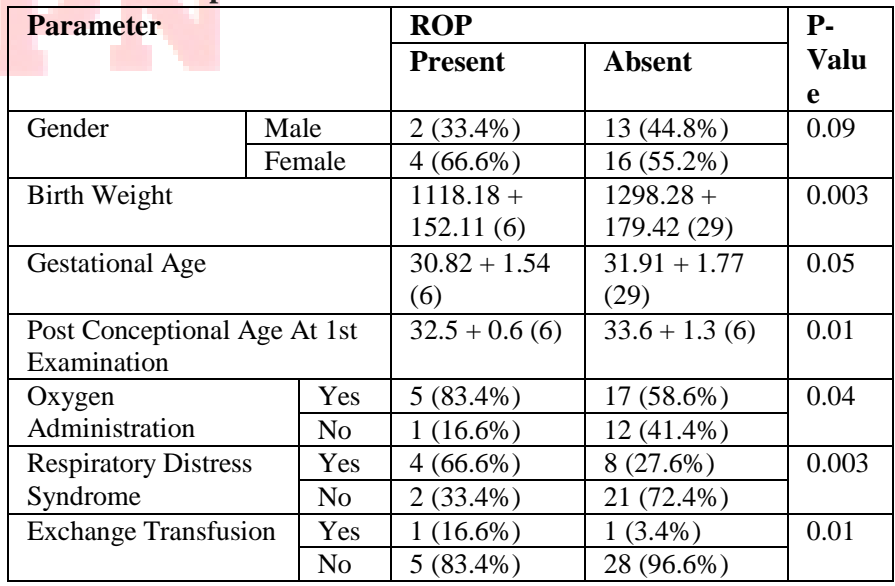

\section{Discussion}

Retinopathy of prematurity is a bilateral vaso-proliferative retinopathy affecting preterm or low birth weight babies which may progresses to cause visual impairment or blindness. It is an avoidable cause of childhood blindness and its control is given priority in WHO's VISION 2020 programme. 8 For early treatment to prevent blindness, 


\section{Kallur \& Muralidhar; Retinapathy of Prematurity in a Teritiary Care Center}

requires a qualified pediatric ophthalmologist to screen babies at risk soon after birth.

Table 3: Comparision of incidence of ROP

\begin{tabular}{|l|l|}
\hline Study & Overall ROP (\%) \\
\hline Present study & 17.1 \\
\hline Narang A et al, ${ }^{[0]} 2004$ & 21 \\
\hline Patil J et al, ${ }^{[10]} 1997$ & 17.5 \\
\hline Gupta VP et al, ${ }^{[1]} 2003$ & 21.7 \\
\hline Maheshwari Ret al, ${ }^{[12]} 1996$ & 20 \\
\hline
\end{tabular}

\section{Conclusion}

Low birth weight and prematurity are important risk factors for ROP. Meticulous fundus examination with indirect ophthalmoscopy in all preterm babies with birth weight $\leq$ $1500 \mathrm{gms}$ is an essential non-invasive method for early detection of ROP and its progression. Screening should be intensified in the presence of factors like RDS, oxygen administration and exchange transfusion. Early detection of ROP cases and timely referral for early treatment prevents blindness.

\section{References}

1. Rekha W, Battu RR. Retinopathy of prematurity: incidence and risk factors. Indian pediatrics. 1996 Dec 1;33:999-1004. (Last accessed on 30/01/2020).

2. Charan R, Dogra MR, Gupta A, Narang A. The incidence of retinopathy of prematurity in a neonatal care unit. Indian journal of ophthalmology. $1995 \mathrm{Jul}$ 1;43(3):123. (Last accessed on 29/01/2020).

3. American Academy of Pediatrics. An international classification of retinopathy of prematurity. Pediatrics. 1984 Jul 1;74(1):127-33. (Last accessed on 25/01/2020).

4. Cloherty JP. Auditory and Ophthalmologic problems. Manual of neonatal care; Lippincott: 5th edition, 677-683. (Last accessed on 28/01/2020)

5. Jalali S, Anand R, Kumar H, Dogra MR, Azad R, Gopal L. Programme planning and screening strategy in retinopathy of prematurity. Indian journal of ophthalmology. 2003 Mar 1;51(1):89. (Last accessed on 29/01/2020).

6. Pejaver RK, Vinekar A, Bilagi A. National neonatology foundation's evidence based clinical practice guidelines 2010. Retinopathy of Prematurity (NNF India, Guidelines). 2010:253-62. (Last accessed on 28/01/2020).

7. Deepak Chawla, Ramesh Agarwal,M. Jeevasankar Ashok Deorari, Vinod K Paul. Retinopathy of Prematurity. 2007. WHO Collaborating Centre for Training \& Research in Newborn Care Division of Neonatology, Department of Pediatrics, All India Institute of Medical Sciences Ansari Nagar, New Delhi. Available from: https://www.newbornwhocc.org/pdf/ROP_new170108.pdf0 (Last accessed on 28/01/2020).

8. Gilbert C, Foster A. Childhood blindness in the context of vision 2020 - the right to sight. WHO Bulletin 2001; 79: 227 - 232. (Last accessed on $01 / 02 / 2020$ ).

9. Narang A, Dutta S, Dogra M, Gupta A. Risk factors of threshold retinopathy of prematurity. Indian Pediatrics 2003; 41: 665-670. (Last accessed on 28/01/2020)

10. Patil J, Deodhar J, Wagh S, Pandit AN. High risk factors for development of retinopathy of prematurity. Indian Pediatrics 1997; 34: 1024-1027. (Last accessed on 29/01/2020).

11. Gupta VP, Dhaliwal U, Sharma R, Gupta P, Rohatgi J. Retinopathy of prematurity - Risk factors. Indian J Pediatrics 2004; 71:887-892. (Last accessed on 02/02/2020)

12. Maheshwari R, Kumar H, Paul VK, Singh M, Deorari AK, Tiwari AK. Incidence and risk factors of retinopathy of prematurity in a tertiary care newborn unit in New Delhi. Natl Med J Ind 1996; 9(5): 211-214. (Last accessed on 03/02/2020)

Copyright: (C) the author(s), 2020. It is an open-access article distributed under the terms of the Creative Commons Attribution License (CC BY 4.0), which permits authors to retain ownership of the copyright for their content, and allow anyone to download, reuse, reprint, modify, distribute and/or copy the content as long as the original authors and source are cited.

How to cite this article: Kallur MB, Muralidhar K. A Prospective Study on Retinopathy of Prematurity in a Teritiary Care Center. Asian J. Clin. Pediatr. Neonatol.2020;8(1):58-60.

DOI: dx.doi.org/10.47009/ajcpn.2020.8.1.14

Source of Support: Nil, Conflict of Interest: None declared. 